\title{
Commentary
}

\section{The parallels between COVID-19 and the Spanish flu of 1918}

\author{
Markordor Lyngdoh*
}

\begin{abstract}
Department of Community Medicine, North Eastern Indira Gandhi Regional Institute of Health and Medical Sciences, Mawdiangdiang, Meghalaya, India
\end{abstract}

Received: 16 August 2020

Accepted: 02 October 2020

\section{*Correspondence:}

Dr. Markordor Lyngdoh,

E-mail: marsangriang@gmail.com

Copyright: ( $)$ the author(s), publisher and licensee Medip Academy. This is an open-access article distributed under the terms of the Creative Commons Attribution Non-Commercial License, which permits unrestricted non-commercial use, distribution, and reproduction in any medium, provided the original work is properly cited.

\begin{abstract}
The 1918 influenza pandemic was the most severe pandemic in recent history. It was caused by an H1N1 virus with genes of avian origin. On the other hand, the ongoing COVID-19 pandemic caused by a novel coronavirus hailed by the world health organization as a "once in a century health crisis" which has led to devastating impacts to health and livelihood the world over. The prevailing situation is reminiscent of the Spanish flu where definitive cure is unavailable and the public health measures like quarantine, social distancing, hand hygiene and isolation are the only alternatives. Both these diseases are transmitted through respiratory droplets, highly contagious and target the respiratory organs. The parallels between these two events cannot be denied. The Spanish flu thrived at a time when the knowledge and availability of antivirals and vaccine development were inadequate. This article strives to highlight a little more on these two separate pandemics and observe their similarities as well as their differences.
\end{abstract}

Keywords: COVID-19, Spanish flu 1918, Similarities

\section{INTRODUCTION}

Theodore Roosevelt once said "The more you know about the past, the better prepared you are for the future". We are now living in uncertain times. The events of the past few months have changed the way we live and initiated a new normal way of living, one we are yet to be acquainted with. The COVID-19 outbreak which was declared as a pandemic on 11th March 2020 has caused not only a global health crisis but caused economic, environmental and social upheaval that will take a long time to recover. At the time of writing this article, there has been 2.27 million cases and 45,257 deaths all over the world.

The more that is being written about COVID-19, the more reminiscent it is of the Spanish flu of 1918 which affected an estimated one-third (approximately 500 million) of the world's population and caused about 50 million deaths worldwide. As is implied in the name COVID-19, 'CO' stands for 'corona,' 'VI' for 'virus,' and ' $\mathrm{D}$ ' for disease, and 19 represents the year of its occurrence. Coronavirus is a single stranded RNA virus with a diameter ranging from 80 to $120 \mathrm{~nm}^{1}{ }^{1}$ The causative agent in the 1918 pandemic is the H1N1 virus. The impact of this pandemic was not limited to 19181919. All influenza a pandemics since that time, and indeed almost all cases of influenza A worldwide (excepting human infections from avian viruses such as H5N1 and H7N7), have been caused by descendants of the 1918 virus, including "drifted" H1N1 viruses and reassorted $\mathrm{H} 2 \mathrm{~N} 2$ and $\mathrm{H} 3 \mathrm{~N} 2$ viruses. ${ }^{2}$ Even though the causative agent of both these pandemics are different, it is essential to see the parallels between them to enable us to determine the way forward and learn from the past.

\section{THE 1918 SPANISH FLU}

The 1918 "Spanish flu" was the fastest spreading and most deadly influenza pandemic in recorded history. 3 Unlike most subsequent influenza virus strains that have developed in Asia, the "first wave" or "spring wave" of 
the 1918 pandemic seemingly arose in the military forts of the United States in March 1918. ${ }^{4}$ Gradually the disease spread at an alarming rate in Europe. Due to wartime censorship, Britain France, Germany and the United States restricted early reports of the ongoing spread of the disease. However, Spain, being a neutral country conveyed all the horrid details of this pandemic and hence the disease became known as the "Spanish flu".

It is possible that a mutation or reassortment occurred in the late summer of 1918, resulting in significantly enhanced virulence. The main wave of the global pandemic, the "fall wave" or "second wave," occurred in September-November 1918. In many places, there was yet another severe wave of influenza in early $1919 .{ }^{5}$

One of the characteristics of pandemic influenza is predilection for young adults. ${ }^{6}$ The clinical course of the condition may be divided for convenience into three stages. The first lasts from three to four days, and is characterized by chills, fever, muscular pain, etc. The second is of rather uncertain duration, and is characterized by involvement of the respiratory system varying in degree from a slight catarrhal condition to the involvement of a large area of one or both lungs. The third is characterized by disturbances of the circulatory system, dyspnea and cyanosis. ${ }^{7}$ According to The Centre of Disease Control, the case-fatality rate of the Spanish Flu was $>2.5 \%$. The majority of individuals who died during the pandemic succumbed to secondary bacterial pneumonia since no antibiotics were available in 1918. However, a subset died rapidly after the onset of symptoms, often with either massive acute pulmonary hemorrhage or pulmonary edema, often in less than five days. $^{2}$

Non-pharmaceutical interventions which were advocated during this time included mandatory (1) Isolation of sick persons and quarantine of their contacts (2) School closures (3) Bans on public gatherings. Markel et al found that cities that acted early, and employed all three tactics, experienced a much milder outbreak than those who delayed or took half measures. ${ }^{8}$ Indeed, some cities served as their own controls if the measures were not steadily applied; if after a growing mortality from influenza became evident, the city imposed these measures; then when the situation improved, the bans were lifted - and a second epidemic peak followed. Some communities, such as San Francisco, made the wearing of masks compulsory in public. ${ }^{9}$ These interventions helped to curb the spread of Spanish flu, in a period in which no effective vaccines or antivirals were available. ${ }^{10}$

\section{COVID-19}

The earliest report of COVID-19 originated in December 2019 in Wuhan, Hubei Province, China. It was reported that most patients had the contact history with Huanan seafood market. The patients presented with fever and cough symptoms. On 7 January 2020, a novel coronavirus was identified in the throat swab sample of one patient by the Chinese center for disease control and prevention (CDC), and was subsequently named as $2019 \neg \mathrm{nCoV}$ by world health organization (WHO). ${ }^{11,12}$ As the situation got worse, the WHO declared the outbreak as the public health emergency of international concern (PHEIC). ${ }^{13}$ On 11 February 2020, the international committee on taxonomy of viruses renamed the virus as severe acute respiratory syndrome coronaviruse-2 (SARS-CoV-2). ${ }^{14}$

India is witnessing an immense growth in the number of confirmed cases of COVID-19 and is currently ranked 3rd in the world. This is seen in spite of the fact that India was quick to close its international borders and enforce the world's largest COVID lockdown on March 22, $2020 .^{15}$ Whether our country has reached the peak of infections is yet to be ascertained. The European countries, on the other hand, have started easing the lockdown restrictions as well as opening their tourism industry. Countries like Italy, France and Spain are now seeing a surge of new cases causing a worry about the possibility of a second wave.

The incubation period of COVID-19 is thought to be up to14 days following exposure. ${ }^{16}$ The symptoms of COVID-19 are usually fever, cough, sore throat, breathlessness, fatigue, malaise among others. The disease is mild in most people; in some (usually the elderly and those with comorbidities), it may progress to pneumonia, acute respiratory distress syndrome (ARDS) and multi organ dysfunction. Many people are asymptomatic. ${ }^{17}$ For COVID-19, as for many infectious diseases, the true level of transmission is frequently underestimated because a substantial proportion of people with the infection are undetected either because they are asymptomatic or have only mild symptoms and thus typically fail to present at healthcare facilities. ${ }^{18,19}$ According to the $\mathrm{WHO}$, most estimates of fatality ratios have been based on cases detected through surveillance and calculated using crude methods, giving rise to widely variable estimates of CFR by country- from less than $0.1 \%$ to over $25 \%$. A large part of the variation in CFRs across countries may be due to the ages of individuals who are tested and identified. One consistent pattern across countries is that the COVID-19 CFR rises sharply over age. ${ }^{20}$ This is in contrast with the Spanish Flu which had a higher mortality rate among the younger age group.

The same non-pharmaceutical interventions that were advocated during the Spanish Flu are being utilized now. Quarantine and isolation have become the mainstay of containment of infections. Hand-hygiene and social distancing are terms that we now use every day in normal conversations. Contact tracing is being used to identify potential patients. 


\section{CONCLUSION}

Both the Spanish flu and COVID-19 are spread by respiratory droplets and mainly target the respiratory system. However, the viruses causing these diseases are different. One is the influenza virus while the other is a new strain of coronavirus. The navigation of the present pandemic is unclear as there is a lack of information. The difference between 1918 and today is that we have made massive strides in scientific technology that the arrival of a vaccine will be sooner rather than later. Although, no specific treatment for COVID-19 is yet known, antivirals like remsedevir and favipiravir are available in the market. The only thing, we as individuals can do is to continue practising the preventive measures that has been advocated from the beginning in an effort to keep ourselves safe as well as prevent the spread of infections to others. As the saying goes "prevention is better than cure".

Funding: No funding sources Conflict of interest: None declared

Ethical approval: Not required

\section{REFERENCES}

1. Chakraborty I, Maity P. COVID-19 outbreak: Migration, effects on society, global environment and prevention. Sci Tot Environt. 2020:138882.

2. Taubenberger JK, Morens DM. 1918 Influenza: the mother of all pandemics. Revista Biomedica. 2006;17(1):69-79.

3. Olson DR, Simonsen L, Edelson PJ, Morse SS. Epidemiological evidence of an early wave of the 1918 influenza pandemic in New York City. Proceed Nation Acade Sci. 2005;102(31):11059-63.

4. Taubenberger JK. The origin and virulence of the 1918 "Spanish" influenza virus. Proceed Americ Philosophi Soc. 2006;150(1):86.

5. Jordan E. Epidemic influenza: A survey. Chica: Americ Medic Assoc. 1927;355.

6. Erkoreka A. The Spanish influenza pandemic in occidental Europe (1918-1920) and victim age. Influen Respirat Virus. 2010;4(2):81-9.

7. Klein HA. The Treatment of Spanish Influenza. J Americ Medic Assoc. 1918;71(18):1510.

8. Markel H, Lipman HB, Navarro JA, Sloan A, Michalsen JR, Stern AM et al. Nonpharmaceutical interventions implemented by US cities during the 1918-1919 influenza pandemic. J Am Med Assoc 2007;298:644-54.
9. Humphreys M. The influenza of 1918: Evolutionary perspectives in a historical context. Evolution, medicine, and public health. 2018;2018(1):219-29.

10. 10. Martini M, Gazzaniga V, Bragazzi NL, Barberis I. The Spanish Influenza Pandemic: a lesson from history 100 years after 1918. J Prevent Medic Hygie. 2019;60(1):E64-7.

11. Huang C, Wang Y, Li X, Ren L, Zhao J, Hu Y, et al. Clinical features of patients infected with 2019 novel coronavirus in Wuhan, China. Lanc (London, England). 2020;395:497-506.

12. Chen N, Zhou M, Dong X, Qu J, Gong F, Han Y, et al. Epidemiological and clinical characteristics of 99 cases of 2019 novel coronavirus pneumonia in Wuhan, China: a descriptive study. Lanc. 2020;395:507-13.

13. 13. Zarocostas J. What next for the coronavirus response?. Lanc. 2020;395:401.

14. International Committee on Taxonomy of Virus. Naming the 2019 Coronavirus (2020). Available at: https://talk.ictvonline.org/. Accessed on 11 Aug 2020.

15. Narayanan L, Pandit M, Basu S, Karmakar A, Bidhan V, Kumar H, et al. Impact of lockdown due to COVID-19 outbreak: Lifestyle changes and Public Health Concerns in India.

16. Wang D, Yin Y, Hu C, Liu X, Zhang X, Zhou S, et al. Clinical course and outcome of 107 patients infected with the novel coronavirus, SARS-CoV-2, discharged from two hospitals in Wuhan, China. Critic Car. 2020;24:1-9.

17. Singhal T. A review of coronavirus disease-2019 (COVID-19). Ind J Pediat. 2020;13:1-6.

18. Kim GU, Kim MJ, Ra SH, Lee J, Bae S, Jung J, et al. Clinical characteristics of asymptomatic and symptomatic patients with mild COVID-19. Clin Microbiol Infect. 2020;26:948.e1-3.

19. Nishiura H, Kobayashi T, Miyama T, Suzuki A, Jung S-M, Hayashi K, et al. Estimation of the asymptomatic ratio of novel coronavirus infections (COVID-19). Int J Infect Dis. 2020;94:154-5.

Sudharsanan N, Didzun O, Bärnighausen T, Geldsetzer P. The Contribution of the Age Distribution of Cases to COVID-19 Case Fatality Across Countries: A 9-Country Demographic. Ann Intern Med. 2020;M20-2973.

Cite this article as: Lyngdoh M. The parallels between COVID-19 and the Spanish flu of 1918. Int J Community Med Public Health 2020;7:4687-9. 